\title{
A DIGNIDADE DA PESSOA HUMANA COMO PRINCÍPIO CONSTITUCIONAL ESTRUTURANTE DO DIREITO ADMINISTRATIVO
}

\section{The dignity of the human being as a constitutional principle that has structured administrative law}

\section{José Sérgio da Silva Cristóvam'}

\begin{abstract}
Resumo: $O$ presente ensaio aborda o tema da dignidade da pessoa humana como princípio constitucional estruturante do Direito Administrativo, a partir da construção de um renovado regime jurídico administrativo,
\end{abstract}

\begin{abstract}
This paper discusses the theme of human dignity as a structural constitutional principle of Administrative Law, from the construction of a new legal administrative system, with the crossing of a more authoritarian
\end{abstract}

1 Doutor em Direito Administrativo pela UFSC (2014), com estágio de Doutoramento Sanduíche no Instituto Superior de Ciências Sociais e Políticas (ISCSP) da Universidade Técnica de Lisboa (Portugal). Mestre em Direito Constitucional pela UFSC (2005). Especialista em Direito Administrativo pelo CESUSC (2003). Professor de Direito Administrativo nos Cursos de Graduação e Pós-Graduação em Direito do CESUSC. Professor de Direito Administrativo na ESMESC, na ESA-OAB/SC e na ENA/Brasil, em convênio com a École Nationale d'Administration (I'ENA/França), bem como em Cursos de Pós-Graduação em Direito da UNIDAVI, UNOESC, UNISUL, UnC, Estácio de Sá e diversas outras instituições. Membro fundador e Presidente do Instituto Catarinense de Direito Público (ICDP). Membro fundador do Instituto de Direito Administrativo de Santa Catarina (IDASC) e da Academia Catarinense de Direito Eleitoral (ACADE). Membro efetivo do Instituto dos Advogados de Santa Catarina (IASC). Conselheiro Estadual da OAB/SC (triênio 2013-2015). Vice-Diretor Geral da ESA-OAB/SC (triênio 2013-2015). Presidente do Comitê de Mobilização para a Reforma Política (OAB/SC). Membro da Comissão de Direito Constitucional e da Comissão da Moralidade Pública da OAB/SC (triênio 20132015). Assessor Jurídico do Sindicato dos Trabalhadores na Rede Estadual de Ensino de Santa Catarina (SINTE/SC). Advogado militante na seara do Direito Público. E-mail: jscristovam@gmail.com 
com a travessia de um modelo mais autoritário, imperativo e autocrático de Administração Pública (paradigma tradicional), para uma perspectiva mais consensual, dialógica, isonômica, democrática e de construção plural das decisões administrativas (paradigma da Administração Pública democrática).

Palavras-chave: Dignidade da pessoa humana. Princípios constitucionais estruturantes. Regime jurídico administrativo. Administração pública democrática. model, and autocratic imperative of Public Administration (traditional paradigm) for a more consensual perspective, dialogic, isonomic, democratic and plural construction of administrative decisions (paradigm of Public Administration democratic).

Keywords: Human dignity. Structural constitutional principles. Legal administrative system. Public administration democratic.

\section{INTRODUÇÃO}

O discurso do novo constitucionalismo trouxe consigo a recuperação da centralidade do debate em torno da dignidade da pessoa humana. Seguramente, essa é uma das mais (ou a mais) ricas, fecundas e recorrentes temáticas de toda a metodologia constitucional contemporânea. Até pela abrangência e os variados enfoques, que transbordariam os limites deste estudo, a abordagem da noção de dignidade humana ficará limitada aos seus contornos básicos, no mais das vezes relacionados ao enfoque principal do regime jurídico administrativo. ${ }^{2}$

2 Para uma análise panorâmica do princípio da dignidade da pessoa humana, seus fundamentos históricos e filosóficos e sua estrutura normativa, consultar: BARCELLOS, Ana Paula de. A eficácia jurídica dos princípios constitucionais: o princípio da dignidade da pessoa humana. Rio de Janeiro: Renovar, 2002; HABERMAS, Jürgen. Um ensaio sobre a Constituição da Europa. Tradução de Marian Toldy e Teresa Toldy. Coimbra: Almedina, 2012, p. 27-57; MIRANDA, Jorge. A dignidade da pessoa humana e a unidade valorativa do sistema de direitos fundamentais. In: MIRANDA, Jorge (Org.). Estudos em homenagem ao Prof. Doutor Martim de Albuquerque. v. I. Coimbra: Coimbra Editora, 2010, p. 933-949; MIRANDA, Jorge; SILVA, Marco Antonio Marques da (Coord.). Tratado luso-brasileiro de dignidade humana. São Paulo: Quartier Latin, 2008; SARLET, Ingo Wolfgang. Dignidade da pessoa humana e direitos fundamentais na Constituição Federal de 1988. 4. ed. Porto Alegre: Livraria do Advogado, 2006. 
A tamanha confiança depositada no resgate do lugar de honra da dimensão humanística, como freio e barreira àqueles mais sombrios e degradantes episódios de guerras que varreram a Europa na primeira metade do século XX, tem levado a filosofia e a dogmática constitucional a reservar-lhe um dos mais altaneiros tronos de fundamento axiológico-normativo de toda ordem constitucional, uma espécie de reitora máxima do Estado constitucional de direito. Nesse sentido, o constitucionalista pátrio Paulo BONAVIDES chega a defendê-la, em uma retórica de inegável exortação, como a "norma das normas dos direitos fundamentais, elevada assim ao mais alto posto da hierarquia jurídica do sistema”. Um princípio que estabelece limites à ação estatal e protege a liberdade humana, pelo que "sua densidade jurídica no sistema constitucional há de ser portanto máxima e se houver reconhecidamente um princípio supremo no trono da hierarquia das normas, esse princípio não deve ser outro senão aquele em que todos os ângulos éticos da personalidade se acham consubstanciados". (BONAVIDES, 2003, p. 232-233).

Com efeito, a centralidade do princípio da dignidade humana e sua condição de base axiológica dos sistemas constitucionais contemporâneos estão decantadas no discurso jurídico ocidental, desde as últimas décadas do século passado. Por outro lado, tanto naquelas ordens constitucionais em que a dignidade da pessoa humana ainda não consta expressamente positivada, como nos sistemas que a colocam como princípio fundamental do Estado democrático de direito (caso brasileiro), não se pode desconsiderar que "o projeto normativo, por mais nobre e fundamental que seja, nem sempre encontra eco na práxis ou, quando assim ocorre, nem sempre para todos ou de modo igual para todos". (SARLET, 2006, p. 26).

Não se pode negar que, da tatuagem normativa constitucional à fotografia da realidade das ruas e dos corredores palacianos dos órgãos estatais, há sempre uma desfocada e pouco nítida expressão de efetividade daqueles quadros normativos. Nada obstante, malgrado o inegável e ainda elevado deficit 
de concretização do princípio da dignidade humana na realidade sensível da sociedade brasileira, ressoa inegável o seu enorme potencial libertário e progressista, enquanto princípio fundamental do Estado democrático de direito (art. 1º, III da $\mathrm{CF} / 88$ ). Em uma ordem constitucional como a brasileira, fortemente marcada por uma perspectiva axiológica e substantiva de promessas e compromissos liberais e sociais, a concretização da Constituição representa um projeto contínuo, multifário e sempre inacabado, uma espécie de utopia concreta, emancipatória e vinculativa, um reluzente e insuprimível farol ético, político e normativo a apontar na direção de uma comunidade cada vez mais justa e igualitária (ou menos injusta e desigual).

Nessa atmosfera sociopolítica ainda bastante hostil à igualdade material e de brutais contrastes sociais, a normatização da dignidade humana como princípio fundamental desempenha um papel decisivo, uma baliza constante a direcionar a sociedade e principalmente os poderes constituídos, inclusive sob pena de uma inequívoca crise de legitimidade, que pode tomar variadas formas, desde a apatia política até movimentos radicais de contestação, cada vez mais visíveis e acentuados, uma medida fiel de que se está a alcançar maiores níveis de maturidade democrática e consciência de cidadania, mesmo que exista uma elevada dose de ruídos, tensões e interferências nesse diálogo. Antes, porém, do debate em torno da dignidade humana como princípio constitucional estruturante do Direito Administrativo, convém que se apresentem as linhas gerais desse novo regime jurídico administrativo, que marca o paradigma da Administração Pública democrática.

\section{O NOVO REGIME JURÍDICOADMINISTRATIVO E SEUS PRINCÍPIOS CONSTITUCIONAIS ESTRUTURANTES}

O fenômeno da constitucionalização do Direito, com profundos reflexos na metodologia constitucional contemporânea, está a destacadamente colonizar a dogmática jurídico- 
-administrativa, a partir da edificação de um sofisticado e abrangente sistema constitucional administrativo. A atual disciplina administrativa não pode prescindir de uma concepção umbilicalmente vinculada à matriz constitucional, o conjunto de normas constitucionais que conformam o atual regime jurídico administrativo.

Mas a adequada e sistematizada concepção de um regime jurídico administrativo, constitucionalmente vinculado enquanto estrutura normativa e conjunto de finalidades e objetivos, deve vir acompanhada da construção normativo-axiológica das suas linhas mestras (princípios estruturantes). Se considerada a superação (total ou parcial) daquele paradigma tradicional, que fundava e legitimava o regime jurídico administrativo no princípio da supremacia do interesse público, com a decorrência do assimétrico e verticalizado sistema de poderes e prerrogativas da Administração Pública, impõe-se a reconstrução das bases de justificação e conformação sistemática desse regime, agora sobre fundamentos estruturantes capazes de afinar o diálogo e manter uma dialética de legitimidade sinfônica com todo o arranjo normativo constitucional, sob a batuta instrumental e horizontalizante do Estado constitucional de direito e do paradigma emergente da Administração Pública democrática. $^{3}$

Nesse contexto, em que se desenha o paradigma emergente da Administração Pública democrática, despontam como princípios estruturantes da disciplina administrativa a dignidade da pessoa humana, o Estado democrático de direito e o princípio republicano, não como parâmetros normativos que possam

3 Para uma análise aprofundada sobre a questão da superação do paradigma tradicional da supremacia do interesse público, bem como a construção do novo regime jurídico administrativo comum ao paradigma da Administração Pública democrática, a partir dos princípios constitucionais estruturantes da dignidade da pessoa humana, do Estado democrático de direito e do princípio republicano, consultar: CRISTÓVAM, José Sérgio da Silva. O conceito de interesse público no Estado constitucional de direito: o novo regime jurídico administrativo e seus princípios constitucionais estruturantes. 2014. 379 f. Tese (Doutorado em Direito) - Programa de Pós-Graduação em Direito da Universidade Federal de Santa Catarina, Florianópolis, 2014. 
isoladamente sustentar o regime jurídico administrativo, mas como verdadeira trindade principiológica estruturante assecuratória dos padrões de unidade interior e adequação valorativa conformadores de todo o edifício constitucional administrativo. A partir de uma leitura sistemática e comprometida com a plena efetividade das normas constitucionais, o regime jurídico administrativo, assim submetido a um verdadeiro "choque de constitucionalização”, resplandece renovado e reestilizado em seus conceitos e nos contornos dos institutos tradicionais. Não por qualquer irresponsável ou pouco ilustrada doutrina de simples abandono daquele modelo, mas por uma profunda e radical revisão da sua lógica conceitual e dos seus limites operacionais e normativos.

Por princípios estruturantes, expressão recorrentemente referida, pode-se entender aquelas "traves-mestras jurídico-constitucionais do estatuto jurídico do político", as diretrizes normativas fundamentais, constitutivas e indicativas "das ideias directivas básicas de toda a ordem constitucional”. Assim concebidos, os princípios estruturantes acabam por alcançar concretização pela via de outros princípios e regras constitucionais de densificação, que iluminam "o seu sentido jurídico-constitucional e político-constitucional, formando, ao mesmo tempo, com eles, um sistema interno”. (CANOTILHO, 2003, p. 1173-1174).

Nessa quadra, com esteio na doutrina do constitucionalista lusitano José Joaquim Gomes CANOTILHO (2003), vale esclarecer que os princípios estruturantes ganham concretização político-normativa a partir do correspondente conjunto de "princípios gerais fundamentais" (princípios constitucionais gerais densificadores), dos "princípios constitucionais especiais” (princípios constitucionais setoriais de densificação) e também do sistema de regras constitucionais, qualquer que seja a sua natureza (regras de organização - regras de competência, de criação de órgãos, de procedimentos; regras materiais - de direitos fundamentais, de garantias institucionais, definidoras de tarefas do Estado, constitucionais impositivas). 
Esse conjunto normativo de princípios (gerais e especiais) e regras constitucionais conforma e funda a própria noção de sistema normativo, também a partir da importante densificação ponderacionista dos círculos de conformação legislativa e de concretização administrativa e judicial. Alerte-se que aqui não se cogita de um sentido estático ou qualquer concepção diretiva hierarquizada (dos princípios gerais para os especiais e depois para as regras), mas uma noção dinâmica, aberta, dialética e orgânica, em uma espécie de razão substantiva, adjetiva e instrumental da própria perspectiva de regime jurídico administrativo, sob as bases do Estado constitucional de direito e dos parâmetros da juridicidade administrativa.

Os firmes ventos de constitucionalização do Direito Administrativo exigem o abandono da lógica tradicional, quase sempre informada por um epicentro normativo e conceitual de dimensão estatal. No salão nobre da juridicidade administrativa abre-se agora a mesa de honra para a perspectiva axiológico-normativa da dignidade humana, do Estado democrático de direito e do princípio republicano. A própria finalidade precípua (compromisso genético) da Administração Pública está em fazer-se prisioneira cativa da promoção e defesa dos direitos fundamentais, base não só para os fins da atividade administrativa, mas também fundamento de legitimidade à própria existência estatal. Segue-se, pois, para o debate do princípio da dignidade da pessoa humana, como princípio estruturante desse novo regime jurídico administrativo.

\section{SOBRE O PRINCÍPIO DA DIGNIDADE DA PESSOA HUMANA: ANTECEDENTES HISTÓRICOS E FILOSÓFICOS}

Antes do debate relacionado à perspectiva conceitual e normativa da dignidade humana, importa promover uma (ainda que) breve recuperação da sua perspectiva histórica. Essa genealogia remete à Antiguidade clássica grega, em que a noção 
de dignidade da pessoa estava muito relacionada à posição que cada indivíduo ocupava na comunidade política. Para a filosofia política aristotélica, fundada em uma concepção organicista de sociedade, cada indivíduo faz parte do corpo orgânico da sociedade, desempenhando sua respectiva função social. Tanto que a concepção de felicidade ou vida boa do indivíduo (bem supremo aristotélico) somente seria atingível por meio da convivência na pólis, onde cada qual cumpriria a sua respectiva função. Esse modelo de comunidade política permite que se possa falar em uma "quantificação e modulação da dignidade, no sentido de se admitir a existência de pessoas mais dignas ou menos dignas". (ARISTÓTELES, 2009, p. 13-17).

Mas o constitucionalista gaúcho Ingo Wolfgang SARLET esclarece que, ainda na Antiguidade clássica, a partir do pensamento estoico, ${ }^{4}$ a dignidade já era concebida como uma qualidade inerente ao ser humano, um dado intrínseco que o distinguia das demais criaturas, "no sentido de que todos os seres humanos são dotados da mesma dignidade". Também na Antiguidade clássica romana, o pensamento ciceroniano "desenvolveu uma compreensão de dignidade desvinculada do cargo ou posição social", o que permite "reconhecer a coexistência de um sentido moral (seja no que diz às virtudes pessoas do mérito, integridade, lealdade, entre outras, seja na acepção estóica referida) e sociopolítico de dignidade (aqui no sentido de posição social e política ocupada pelo indivíduo)”. (SARLET, 2006, p. 30-31).

Ainda sobre a dimensão histórica, uma das mais influentes e destacadas contribuições à formação política e filosófica da

4 Suplanta os limites do presente estudo a apresentação do estoicismo e seus principais fundamentos filosóficos. Apenas para ilustrar: "O estoicismo, em especial, apoiava o seu Cosmopolitismo em dois elementos fundamentais: na ideia de uma razão universal que regula todas as coisas segundo uma ordem necessária; na consciência de que a razão fornece ao homem normas infalíveis de ação que constituem o direito natural. Além disso, o estoicismo, ao exaltar os valores intelectuais, fazia consistir a distinção entre o sábio e os demais homens justamente na consciência da caducidade dos ideais da pátria e do Estado." BOBBIO, Norberto; MATTEUCCI, Nicola; PASQUINO, Gianfranco. Dicionário de Política. Tradução de João Ferreira. v. I. 11. ed. Brasília: Editora Universidade de Brasília, 1998, p. 293-294. 
noção de dignidade humana pode ser atribuída à doutrina teológica judaico-cristã. Uma perspectiva humanista de centralidade da pessoa humana, a mais perfeita criatura divina, pode ser recuperada já no Antigo Testamento, no Livro de Gênesis, quando o ser humano é descrito como a imagem e semelhança do Deus criador, com o desígnio celestial de crescer, multiplicar e dominar a Terra. ${ }^{5}$ Com o Novo Testamento e a construção das bases da moralidade cristã, a doutrina fundada no grande mandamento do "amor ao próximo" passa a figurar como um dos principais legados do Cristianismo à noção de dignidade humana. ${ }^{6}$

Com efeito, a teologia cristã ostenta uma posição destacada na reflexão ocidental sobre a dignidade humana, que lhe é herdeira direta, até mesmo na formulação moderna da noção de pessoa, uma concepção antropológica fundada na ideia de imagem e semelhança divina. Essa perspectiva divina e espiritual da noção de pessoa conferiu primeiramente ao termo "dignidade" uma espécie de "função eminente", passando depois para um "atributo por excelência da pessoa". (MAURER, 2005, p. 65-66). Nessa quadra, pode-se recuperar na escolástica tomista as bases de uma original e influente doutrina de autodeterminação e liberdade (arbítrio), não somente no sentido de reconhecer o fundamento da dignidade humana na imagem e semelhança do Criador, mas que "também radica na capacidade de autodeterminação inerente à natureza humana, de tal sorte que, por força de sua dignidade, o ser humano, sendo livre por natureza, existe em função de sua própria vontade”. (SARLET, 2006, p. 31).

Abre-se aqui um parêntese para consignar que toda essa histórica filosofia política da fé cristã, fundada na solidariedade,

5 Do Antigo Testamento, no Livro de Gênesis, capítulo 1, versículo 28: "Crescei e multiplicai-vos, enchei e dominai a Terra" (Gn 1, 28). GÊNESIS. In: A BÍBLIA SAGRADA. Tradução ecumênica. São Paulo: Paulinas, 2002.

6 Do Evangelho segundo São JOÃO, capítulo 15, versículo 12: "Este é o meu mandamento: amai-vos uns aos outros, como eu vos amo" (Jo 15, 12). JOÃO. In: A BÍBLIA SAGRADA. Tradução ecumênica. São Paulo: Paulinas, 2002. 
no respeito e no amor ao próximo, não impediu que no seio da Igreja Católica fossem conduzidos alguns dos mais brutais e irracionais movimentos de desrespeito e desconsideração da dignidade humana. Disto serve como mais horroroso e desumano exemplo a chamada Santa Inquisição, que por um longo período assolou boa parte da velha Europa. ${ }^{7}$ Por outro lado, como esclarece o constitucionalista português Jorge MIRANDA, movimentos como a "Doutrina Social da Igreja, as intervenções dos últimos Papas sobre problemas concretos, o Concílio Vaticano II, a ação dos bispos em numerosos países, a iniciativa de diversas comunidades, a oposição de vários grupos a regimes autoritários e totalitários", todos estes fatores revelam "o reencontro dos católicos com os direitos e liberdades fundamentais, assim como importantes contribuições para a mudança de mentalidades e de estruturas em numerosos países, sobretudo na América Latina”. (MIRANDA, 2012, p. 50).

Retomando o debate central, convém dizer que a Modernidade concluiu o processo histórico de secularização e laicização da dignidade humana, encontrando na doutrina kantiana uma das suas mais destacadas e difundidas vertentes filosóficas. Com base em uma noção de dignidade vinculada à perspectiva da autonomia ética do indivíduo, verdadeiro fundamento da noção de dignidade, erige-se a concepção de que a pessoa não pode ser tratada, nem por ela própria, como objeto. A partir da natureza racional do ser humano, a teoria kantiana funda na autonomia da vontade (autodeterminação), comum apenas aos seres racionais, a própria noção secularizada e dessacralizada de dignidade humana. A dignidade humana abandona suas vestes sacrais e assume uma nudez racional-individualista de autodeterminação, que vai acompanhá-la Modernidade afora (SARLET, 2006, p. 32-33).

A partir desses elementos filosóficos, Immanuel KANT estabelece sua célebre doutrina da dignidade humana, fundada

7 Para um estudo sobre a Santa Inquisição, consultar: GONZAGA, João Bernardino. A inquisição em seu mundo. 8. ed. São Paulo: Saraiva, 1994. 
no imperativo de que o ser humano existe como um fim em si mesmo, não como meio ou instrumento, mas como a própria razão última da sua existência. Para ser fiel às exatas palavras do Filósofo de Königsberg, o ser humano "existe como um fim em si mesmo, não simplesmente como meio para uso arbitrário desta ou daquela vontade. Pelo contrário, em todas as suas ações, tanto nas que se dirigem a ele mesmo como nas que se dirigem a outros seres racionais, ele tem sempre de ser considerado simultaneamente como um fim". (KANT, 1980, p. 134).

$\mathrm{Na}$ filosofia kantiana, os seres irracionais cuja existência não depende da vontade humana, mas da própria natureza, possuem um valor relativo (meios) e são chamados de coisas. Assim, os seres racionais (as pessoas) não podem ser usados ou considerados como simples meios, porquanto dotados de dignidade. Dignidade, que na doutrina kantiana, é um fim diverso do preço, pois se "uma coisa tem um preço, pode pôr-se em vez dela qualquer outra como equivalente; mas quando uma coisa está acima de todo preço, e portanto não permite equivalente, então ela tem dignidade", o que permite conhecer e reconhecer "como dignidade o valor de uma tal disposição de espírito e põe-na infinitamente acima de todo o preço". (KANT, 1980, p. 140).

Inegavelmente, as formulações kantianas sobre a dignidade humana representam uma das mais engenhosas e importantes bases para o discurso filosófico e jurídico da Modernidade. Para o Filósofo de Königsberg, a pessoa é dotada de dignidade porque é autônoma e livre. A autonomia representa "o princípio da dignidade da natureza humana e de toda a natureza racional", pelo que "liberdade, autonomia e dignidade formam uma trilogia inseparável”. Mas não uma liberdade no sentido egoístico de fazer o que se quer. Para a filosofia kantiana, "o homem é autônomo quando os seus atos estão em conformidade com a lei moral. Ora, esta lei é universal. O homem age de forma livre quando obedece à razão, e não à sua razão. A intenção deve ser isenta de qualquer interesse pessoal, de qualquer paixão egoísta”. (MAURER, 2005, p. 76). 
Esses breves antecedentes históricos e filosóficos contribuem com necessárias reflexões para que se possa adentrar na dimensão conceitual e normativa da dignidade humana, o debate acerca do seu significado e conteúdo na perspectiva jurídico-constitucional.

\section{A DIGNIDADE HUMANA COMO PRINCÍPIO AXIOLÓGICO FUNDAMENTAL}

A definição do significado e do conteúdo normativo da dignidade humana está longe de representar uma tarefa fácil, muito menos a construção de um conceito capaz abarcar a sua complexidade histórica, cultural, axiológica e normativa, e que possa ser útil e efetivo no seu processo de aplicação, sobretudo como parâmetro de limitação das ações estatais e promoção dos direitos e garantias fundamentais. Essa dificuldade conceitual decorre, em larga medida, da própria vagueza e indeterminação características dos conceitos jurídicos indeterminados, em especial a dignidade da pessoa humana, uma noção polissêmica e marcada por uma elevada dose de ambiguidade e porosidade, submetida a um descontínuo e instável processo de construção e desenvolvimento. ${ }^{8}$

Mas com isso não se quer conduzir à ideia (errônea, por sinal) de que não seria possível a construção de um conceito jurídico de dignidade humana, capaz de alcançar a sua inerente complexidade. Aqui não se está a fazer referência a alguns aspectos da existência humana (integridade física, intimidade, vida), mas a "uma qualidade tida como inerente a todo e qualquer ser humano", no sentido do "valor próprio que identifica o ser humano como tal, definição esta que, todavia, acaba por não contribuir muito para uma compreensão satisfatória do que efetivamente é o âmbito de proteção da dignidade, na sua condição jurídico-normativa”. (SARLET, 2006, p. 40).

8 Nesse sentido, consultar: ROCHA, Cármen Lúcia Antunes. O princípio da dignidade da pessoa humana e a exclusão social. Revista Interesse Público, São Paulo, ano 1, n. 4, p. 23-48, out./dez. 1999, p. 24. 
Para esta parametrização conceitual interessa recuperar os contornos em que foi estabelecida a noção de dignidade humana pela Declaração Universal dos Direitos Humanos da ONU, em 1948, logo após todo aquele estado de horrores e atrocidades que marcaram a Segunda Guerra Mundial. A partir de uma clara matriz kantiana de autonomia e direito de autodeterminação humana, assim prescreve o seu art. 1\%: "Todos os seres humanos nascem livres e iguais em dignidade e em direitos. Dotados de razão e de consciência, devem agir uns para com os outros em espírito de fraternidade." 9

Esses são os contornos pelos quais a dignidade humana se pulverizou pelas Constituições da segunda metade do século passado, com destacado status na Lei Fundamental alemã de 1949 (art. 1.1), na Constituição portuguesa de 1976 (art. 1o) e na Constituição espanhola de 1978 (preâmbulo e art. 10.1), apenas para referir algumas das mais influentes no Segundo Pós-Guerra. No Brasil, com o advento da Constituição Cidadã, a dignidade humana foi alçada à condição de princípio fundamental do Estado democrático de direito (art. 1º, III da CF/88). Há, ainda, previsão expressa no seu art. 170, caput, no sentido de que a ordem econômica tem por finalidade assegurar a todos uma existência digna; também, no art. 226, § 7\%, quando estabelece que o planejamento familiar funda-se nos princípios da dignidade da pessoa humana e da paternidade responsável; no art. 227, caput, quando assegura à criança e ao adolescente o

9 Sobre a temática, importa também registrar as três primeiras justificativas que constam do preâmbulo da Declaração Universal dos Direitos Humanos: "Considerando que o reconhecimento da dignidade inerente e dos direitos iguais e inalienáveis de todos os membros da família humana é o fundamento da liberdade, justiça e paz no mundo; Considerando que o desprezo e o desrespeito pelos direitos humanos resultaram em atos bárbaros que ultrajaram a consciência da Humanidade e que o advento de um mundo no qual os seres humanos gozem de liberdade de expressão e de crença e da liberdade do medo e da miséria, foi proclamado como a mais alta aspiração do homem comum; Considerando que é essencial, para que o Homem não seja obrigado a recorrer, como último recurso, à rebelião contra a tirania e a opressão, que os direitos humanos sejam protegidos pelo estado de direito". ASSEMBLEIA GERAL DAS NAÇÕES UNIDAS. Organização das Nações Unidas (ONU). Declaração Universal dos Direitos Humanos. 10 de dezembro de 1948. Disponível em: <http://www.humanrights.com/pt/what-are-human-rights/ universal-declaration-of-human-rights/preamble.html>. Acesso em: 27 jan. 2014. 
direito à dignidade; por fim, no art. 230, caput, que garante ao idoso o amparo e a defesa da sua dignidade e bem-estar.

Nessa esteira de considerações, sem desprestigiar a perspectiva natural da noção de dignidade humana como uma qualidade inata e algo inerente à natureza humana, SARLET aponta o relevante sentido cultural da ideia de dignidade humana, "fruto do trabalho de diversas gerações e da humanidade em seu todo, razão pela qual as dimensões natural e cultural da dignidade da pessoa se complementam e interagem mutuamente". (SARLET, 2006, p. 46).

Todos esses elementos históricos, filosóficos e culturais conduzem o constitucionalista pátrio a oferecer uma sofisticada e aberta conceituação jurídica de dignidade da pessoa humana, aqui integralmente compartilhada e subscrita, enquanto qualidade intrínseca e distintiva de todos os seres humanos, que lhes garante igual respeito e consideração por parte do Estado e da comunidade. Isso exige um complexo de direitos e deveres fundamentais, que protejam a pessoa contra todo e qualquer ato degradante e desumano, bem como lhe garantam as mínimas condições existenciais para uma vida saudável, capazes de promover sua participação ativa e corresponsável no seu destino e na vida em comunhão com as outras pessoas. ${ }^{10}$

No Brasil, como inclusive decorre expressamente do texto constitucional, não há maiores celeumas na qualificação da dignidade da pessoa humana como norma jurídica fundamental do Estado constitucional de direito, um princípio axiológico que fundamenta e irradia normatividade para todo o sistema de regras e princípios constitucionais. Como já se disse em outras oportunidades, com o claro deslocamento do epicentro norma-

10 Nas exatas palavras de SARLET: "Assim sendo, temos por dignidade da pessoa humana a qualidade intrínseca e distintiva reconhecida em cada ser humano que o faz merecedor do mesmo respeito e consideração por parte do Estado e da comunidade, implicando, neste sentido, um complexo de direitos e deveres fundamentais que assegurem a pessoa tanto contra todo e qualquer ato de cunho degradante e desumano, como venham a lhe garantir as condições existenciais mínimas para uma vida saudável, além de propiciar e promover sua participação ativa e co-responsável nos destinos da própria existência e da vida em comunhão com os demais seres humanos". (SARLET, 2006, p. 60). 
tivo constitucional do Estado para a pessoa humana, resta inegável que são os poderes constituídos e o aparato estatal que se fundam e legitimam em função da dignidade humana, e não esta que se funda no Estado. O Estado é que funciona como meio (instrumento) de concretização e promoção dos ditames finalísticos substantivos e instrumentais relacionados à dignidade humana, fim e medida de legitimação da normatividade constitucional estabelecida e dos próprios poderes constituídos.

Nesse quadrante, pode-se mesmo sustentar que o princípio da dignidade humana funciona como genuíno parâmetro de consubstancialidade para outros direitos fundamentais. ${ }^{11}$ Como esclarece o filósofo alemão Jürgen HABERMAS, nada obstante a assimetria histórico-temporal entre as concepções de direitos humanos e dignidade humana, esses dois conceitos sempre guardaram um estreito nexo conceitual, embora inicialmente apenas implícito. A invocação dos direitos humanos alimenta-se da indignação dos ofendidos face à violação da sua dignidade humana. Portanto, a dignidade humana reveste-se da qualidade de "fonte moral da qual se alimentam os conteúdos de todos os direitos fundamentais", desempenhando um "papel catalizador" na "composição dos direitos humanos a partir da moral da razão e da sua forma jurídica”, o que "explica a força explosiva, do ponto de vista político, de uma utopia concreta" (HABERMAS, 2012, p. 31-32).

Em suma, a dignidade humana apresenta-se como autêntico princípio axiológico fundamental da ordem constitucional brasileira. Uma estrutura normativa que, afora o seu inegável conteúdo ético e moral (aspecto natural, cultural e filosófico), assume o status de norma formal e materialmente constitucional, dotada de eficácia plena e efeito vinculante a toda ordem normativa estabelecida, às atividades legislativas, administrativas e judiciais, bem como impositiva de respeito e consideração por toda a comunidade política.

11 Nesse sentido: TAVARES, André Ramos. Princípio da consubstancialidade parcial dos direitos fundamentais na dignidade do Homem. Revista da Faculdade de Direito da Universidade de Lisboa, Lisboa, v. XLVII, n. 1 e 2, p. 313-331, 2006, p. 322-330. 
Nesse sentido, ganha destacado relevo a concepção de que o princípio da dignidade humana ostenta uma condição funcional dúplice, sendo simultaneamente limite (dimensão negativa) e tarefa (dimensão positiva) dos poderes estatais, da comunidade e dos particulares. Como um Janus pós-moderno, aponta diretamente para duas dimensões (faces) complementares: uma defensiva (negativa), outra prestacional (positiva). Isso permite a superação (em partes) daquela concepção kantiana de dignidade humana centrada na autonomia e no direito de autodeterminação da pessoa, já que é tarefa do Estado assegurar às pessoas uma mínima condição de vida digna.

Como limite, o princípio da dignidade humana assegura que a pessoa não poderá, em qualquer hipótese, ser reduzida à condição de mero objeto da ação própria ou de terceiros (até mesmo pessoas em quadros vegetativos ou alienados mentais têm direito a um tratamento com respeito humanístico e dignidade). Disso resulta a garantia de direitos fundamentais (negativos) contra atos que violem a pessoa ou a exponham a graves ameaças. Enquanto tarefa, o princípio da dignidade humana impõe deveres concretos dos órgãos estatais, capazes de proteger a dignidade de todos, até mesmo por meio de medidas prestacionais (positivas) que promovam a dignidade humana e assegurem as condições existências mínimas (vida digna) (SARLET, 2005, p. 30-32). Essa dimensão dualista da dignidade humana, aliada à nova topografia constitucional que aponta para a centralidade da pessoa (personalismo constitucional), oferecem valorosas possibilidades de diálogo entre o princípio da dignidade humana e o regime jurídico administrativo.

\section{AS RELAÇÕES ENTRE O PRINCÍPIO DA DIGNIDADE DA PESSOA HUMANA, A SEGURANÇA JURÍDICA, A PROTEÇÃO DA CONFIANÇA LEGÍTIMA, A BOA-FÉ E O PROCESSODISCIPLINAR:ALGUMASCONSIDERAÇÕES}

A densificação do paradigma emergente, que funda o novo regime administrativo, a partir do princípio estruturante 
da dignidade humana, passa por um processo de reconformação e afirmação de uma série de princípios constitucionais expressos e implícitos, que ganham um novo colorido e uma renovada dimensão normativa.

Um dos princípios que reassume lugar de proeminência no novo regime jurídico administrativo é o princípio da segurança jurídica, ${ }^{12}$ sorvendo carga de normatividade e legitimação política diretamente do princípio da dignidade humana, do regime constitucional de direitos fundamentais e da própria noção de justiça da ordem jurídica constitucional. As dimensões constitucionais de liberdade e igualdade reclamam uma sólida noção de estabilidade das relações jurídicas, com a efetiva segurança jurídica dos cidadãos e dos demais atores sociais e econômicos na forma como são aplicadas as leis e nos mecanismos de atuação administrativa. A noção de segurança jurídica toma, assim, uma perspectiva de valor transcendental da própria ordem jurídico-política constitucional, uma das suas mais destacadas finalidades, muito mais sofisticada do que aquela posição estática e prisioneira da legalidade formal do paradigma tradicional.

No Brasil, a proteção da segurança jurídica goza de respaldo constitucional enquanto princípio constitucional implícito, que pode ser extraído diretamente do princípio da dignidade humana (art. 1º, III, da CF/88) e do sistema de proteção aos direitos fundamentais (arts. $5^{\circ}$, caput, e $6^{\circ}$ da CF/88), como também do próprio princípio estruturante do Estado democrático de direto (art. 1º caput, da CF/88). Há, ainda, cláusula constitucional expressa que protege o direito adquirido, o ato jurídico perfeito e a coisa julgada (art. 5, XXXVI, da CF/88), expressões normativas de densificação do princípio da segurança jurídica (BINENBOJM, 2008, p. 177-180).

12 Para um estudo panorâmico do princípio da segurança jurídica e sua relação com o princípio da legalidade, consultar: SILVA, Almiro do Couto. Princípio da legalidade da Administração Pública e da segurança jurídica no Estado de direito contemporâneo. Revista da Procuradoria Geral do Estado do Rio Grande do Sul, Porto Alegre, v. 27, n. 57, p. 11-31, 2004. 
Sobre o tema, o jurista Almiro do Couto e SILVA esclarece que a segurança jurídica ostenta uma dimensão dúplice (objetiva e subjetiva): a primeira, "de natureza objetiva, é aquela que envolve a questão dos limites à retroatividade dos atos do Estado até mesmo quando estes se qualifiquem como atos legislativos. Diz respeito, portanto, à proteção ao direito adquirido, ao ato jurídico perfeito e à coisa julgada"; a outra, "de natureza subjetiva, concerne à proteção à confiança das pessoas no pertinente aos atos, procedimentos e condutas do Estado, nos mais diferentes aspectos de sua atuação". (SILVA, 2004, p. 36).

$\mathrm{Na}$ mesma linha, diretamente vinculado e decorrente do princípio da segurança jurídica, o princípio da proteção da confiança legítima dos cidadãos impõe ao Estado o dever de não frustrar as legítimas expectativas dos indivíduos na manutenção da estabilidade da atuação estatal, ainda que, por vezes, fundada em ilegalidades. Neste quadrante, há situações que produzem na esfera de expectativas do indivíduo uma justa confiança de estabilidade, o que impõe ao Estado "limitações na liberdade de alterar sua conduta e de modificar atos que produziram vantagens para os destinatários, mesmo quando ilegais, atribuindo-se consequências patrimoniais por essas alterações", para preservar a "crença gerada nos beneficiários, nos administrados ou na sociedade em geral de que aqueles atos eram legítimos, tudo fazendo razoavelmente supor que seriam mantidos". (SILVA, 2004, p. 37).

Outro princípio que assume destacada posição normativa nesse renovado regime administrativo é o princípio da boa-fé, também diretamente vinculado ao princípio estruturante da dignidade humana e um dos seus mais ricos e dinâmicos princípios de densificação na seara jurídico-administrativa. O princípio da boa-fé assume a condição de princípio constitucional implícito, sendo que, afora o respaldo direto no princípio da dignidade humana, resta amparado naquelas disposições 
normativas que conferem status constitucional ao princípio da segurança jurídica, ante a sua aproximação operativa. ${ }^{13}$

No âmbito específico do Direito Administrativo, há que se reconhecer, ainda, que o princípio da boa-fé encontra seu status constitucional a partir da dimensão objetiva do próprio princípio da moralidade administrativa (art. 37, caput, da CF/88), pelo que o seu aspecto objetivo "veicula a boa-fé objetiva no campo do direito público-administrativo, exigindo um comportamento positivo da Administração e impondo a ela deveres de conduta transparente e leal". Dessa forma, há casos em que a omissão administrativa pode assegurar ao cidadão um direito subjetivo público a prestações do Poder Público ou a indenizações, de modo que a "proteção à confiança legítima dos administrados é seu principal desdobramento, não havendo, em princípio, óbice para o aproveitamento dos institutos decorrentes da boa-fé objetiva desenvolvida no campo jurídico-privado aos domínios do direito público-administrativo". (GIACOMUZZI, 2001, p. 308-309).

A doutrina especializada comumente distingue o sentido objetivo da boa-fé, do seu aspecto subjetivo. Na interessante síntese de Edilson Pereira NOBRE JUNIOR, a “a boa-fé é valorada, também no direito administrativo, ora como padrão de conduta, a exigir dos sujeitos do vínculo jurídico atuação conforme à lealdade e à honestidade (boa-fé objetiva), ora como uma crença, errônea e escusável, de uma determinada situação (boa-fé subjetiva)". Nesse sentido, o autor ressalta que a hipótese da boa-fé objetiva "alcança maior influência no terreno aplicativo, sendo de grande valia no concernente aos atos e contratos

13 Para um estudo panorâmico sobre o princípio da boa-fé no Direito Administrativo, consultar: ALVES, José Ricardo Teixeira. A tutela da boa-fé objetiva no Direito Administrativo. Jus Navigandi, Teresina, ano 13, n. 1917, set. 2008. Disponível em: <http://jus.com.br/artigos/11783>. Acesso em: 3 fev. 2014; GIACOMUZZI, José Guilherme. A moralidade administrativa e a boa-fé da Administração Pública: o conteúdo dogmático da moralidade administrativa. São Paulo: Malheiros, 2001; NOBRE JÚNIOR, Edilson Pereira. O princípio da boa-fé e sua aplicação no Direito Administrativo brasileiro. Porto Alegre: Sergio Antonio Fabris Editor, 2002. 
administrativos, procedimento administrativo, serviços públicos, atividade reguladora e na responsabilidade estatal na intervenção sobre a ordem econômica”. Já a dimensão da boa-fé "em sua vertente psicológica é suscetível de um mais restrito emprego, sendo de valia quanto às sanções administrativas e em algumas relações entre o Estado e seus servidores". (NOBRE JUNIOR, 2002, p. 150-151).

$\mathrm{Na}$ disciplina jurídico-administrativa, uma das maiores demonstrações de densificação legislativa dos princípios da segurança jurídica, da proteção da confiança legítima dos cidadãos e da boa-fé pode ser recuperada da Lei Federal nº 9.784/1999, em especial no art. $2^{\circ}$, caput (previsão do princípio da segurança jurídica), no art. 2 ${ }^{\circ}$ parágrafo único, IV (atuação segundo padrões éticos de probidade, decoro e boa-fé), no art. 2, parágrafo único, XIII (interpretação da norma administrativa da forma que melhor garanta o atendimento do fim público a que se dirige, vedada aplicação retroativa de nova interpretação), e também no art. 54, caput (decadência administrativa para anulação de atos ilegais com efeitos favoráveis aos destinatários).

O art. 54, caput, da Lei Federal n 9.784/99 representa um excelente exemplo de densificação ponderativa legislativa, no sentido que, antevendo a enorme e recorrente possibilidade de colisões in concreto entre os princípios da legalidade administrativa e da autotutela da Administração Pública, de um lado, e os princípios da segurança jurídica, da proteção da confiança legítima dos cidadãos e da boa-fé administrativa, de outro, a partir da clara ponderação favorável ao princípio estruturante da dignidade humana, mas sem desconsiderar o princípio republicano, o legislador infraconstitucional estabeleceu o prazo decadencial de cinco anos para que o Poder Público possa rever seus atos e os efeitos deles decorrentes, se favoráveis aos destinatários.

Antes do advento da referida ponderação legislativa, a Administração Pública dispunha de um espectro mais amplo de atuação, mas, mesmo assim, já havia a sua obrigação de promover 
a imediata concretização constitucional, com a fixação interna de limites temporais e materiais gerais (não casuísticos) à autotutela e à revisão dos atos administrativos que, embora ilegais, trouxessem efeitos favoráveis aos destinatários, se de boa-fé. $\mathrm{O}$ referido espaço de ponderação administrativa decorre da aplicação direta e imediata do sistema de regras e princípios constitucionais.

Outro importante aspecto de aplicação do princípio estruturante da dignidade humana na disciplina jurídico-administrativa refere-se à seara do processo disciplinar ${ }^{14}$ e do Direito Administrativo sancionatório em geral. ${ }^{15}$ A partir do enfoque humanístico do princípio da dignidade da pessoa, inúmeros princípios constitucionais adquirem um colorido normativo muito mais determinante. Nesse quadrante, a simples leitura sistemática e teleológica dos princípios do devido processo legal administrativo (art. 5 , LIV, da CF/88), do contraditório e da ampla defesa (artigo $5^{\circ}$, LV da $\left.\mathrm{CF} / 88\right)^{16}$ já demonstra o completo descompasso e mesmo a inconstitucionalidade da Súmula Vinculante n. 05, do Supremo Tribunal Federal, quando prescreve que "a falta de defesa técnica por advogado no processo administrativo disciplinar não ofende a Constituição". ${ }^{17}$ Mais do que uma inadequada leitura constitucional, a referida súmula normativa ofende diretamente aos artigos $1^{\circ}$, III, e 5, LV, da Constituição Federal, do que decorre a sua inconstitucionalidade, por contra-

14 Para um estudo panorâmico sobre o processo administrativo disciplinar e seus princípios constitucionais informadores, consultar: BACELLAR FILHO, Romeu Felipe. Processo administrativo disciplinar. 4. ed. São Paulo: Saraiva, 2013.

15 Para um estudo panorâmico sobre o Direito Administrativo sancionatório, consultar: OSÓRIO, Fábio Medina. Direito Administrativo Sancionador. 2. ed. São Paulo: Revista dos Tribunais, 2005.

16 Para uma análise da função democrática do princípio do contraditório no âmbito do processo administrativo disciplinar, consultar: STAFFEN, Márcio Ricardo; CADEMARTORI, Daniela Mesquita Leutchuk de. A função democrática do princípio do contraditório no âmbito do processo administrativo disciplinar: aproximações entre Elio Fazzalari e Jürgen Habermas. In: SILVA, Maria Teresinha Pereira; ZANOTELLI, Maurício (Coord.). Direito e Administração Pública: por uma hermenêutica compatível com os desafios contemporâneos. Curitiba: Juruá, 2011, p. 23-39.

17 Nesse mesmo sentido, consultar: KISTEUMACHER, Daniel Henrique Rennó. A (in) constitucionalidade da Súmula Vinculante $n^{\circ} 5$. Revista de Direitos Fundamentais e Democracia, Curitiba, v. 9, n. 9, p. 292-311, jan./jun. 2011. 
posição direta ao princípio constitucional axiológico-estruturante da dignidade humana e ao princípio constitucional da ampla defesa, que não pode prescindir da defesa técnica, no caso de processos administrativos disciplinares, porquanto diretamente relacionada ao seu núcleo essencial.

Mas não são apenas os princípios do devido processo legal, do contraditório e da ampla defesa que ganham nova dimensão normativa quando da aplicação aos processos administrativos disciplinares. O princípio estruturante da dignidade humana coloniza em tal medida a seara do processo administrativo disciplinar e do Direito Administrativo sancionatório em geral, que todas aquelas disposições de garantias constitucionais penais ao acusado passam a ostentar legítima aplicação, em maior ou menor amplitude, como elementos de garantia ao servidor e ao cidadão em geral. Apenas para exemplificar, seguem algumas disposições constitucionais penais aplicáveis no âmbito do processo administrativo disciplinar e do Direito Administrativo sancionatório em geral: tipicidade penal-administrativa e reserva de lei (art. 5, XXXIX, da CF/88); juiz natural administrativo (art. 5, XXXVII e LIII, da CF/88); presunção de inocência (art. 5, LVII, da CF/88); irretroatividade da legislação penal-administrativa, salvo para beneficiar o servidor (art. $5^{\circ}, \mathrm{XL}$, da $\mathrm{CF} / 88$ ); vedação ao uso de provas obtidas por meio ilícito (art. $5^{\circ}$, LVI, da CF/88).

Cabe ressaltar, ainda, que a atuação legislativa de ponderação e densificação constitucional não faz cessar a possibilidade de novas ponderações concretas pelo Poder Público, para o caso daquelas situações não alcançadas pela mediação legislativa, o que não exclui também o âmbito da ponderação judicial, todas sempre vinculadas à satisfação otimizada das finalidades constitucionais e à prevalência dos direitos fundamentais.

\section{CONCLUSÃO}

Inegavelmente, a partir das considerações acima alinhadas, pode-se sustentar a existência das condições jurídicas instrumen- 
tais e substantivas de transição para um renovado regime jurídico administrativo, com a superação daquele paradigma tradicional estático, fundado na supremacia do interesse público e na lógica da assimetria e verticalização de prerrogativas e privilégios da Administração Pública. Um regime administrativo fundado na trindade principiológica estruturante da dignidade humana, do Estado democrático de direito e do princípio republicano. O modelo de Estado constitucional de direito e a dimensão da juridicidade administrativa constroem as bases para a travessia de um modelo mais autoritário, imperativo e autocrático de Administração Pública, para uma perspectiva mais consensual, dialógica, isonômica, democrática e de construção plural das decisões administrativas (paradigma emergente da Administração Pública democrática).

A unidade principiológica tridimensional desse renovado regime jurídico administrativo comprime amplamente aqueles tradicionais matizes autoritários, assimétricos e verticalizados do agir administrativo, submetendo o Poder Público a um novo parâmetro de legitimação constitucional, o da justificação democrática e da defesa e promoção dos direitos fundamentais. O "legitimômetro constitucional" da Administração Pública somente atinge seus níveis minimamente exigidos, quando a Administração Pública abandona suas vestes autoritárias de autolegitimação, imperatividade e autocracia, e assume uma nudez reveladora de transparência efetiva, de publicidade plena das razões políticas e jurídicas das ações e (sobretudo) omissões administrativas, com a construção das decisões políticas a partir do diálogo franco e aberto com a sociedade, que passa a controlar (direta e imediatamente) a eficiência e os resultados do agir administrativo.

Nesse cenário, os princípios de defesa dos interesses dos cidadãos, como a segurança jurídica, a proteção da confiança legítima e a boa-fé, assumem tonalidades de concretização muito mais decisivas nas situações de conflitos entre interesses, porquanto representam vetores de densificação do princípio da 
dignidade humana. A própria condição de defesa do cidadão ante o Poder Público reclama o mais amplo reconhecimento dos direitos e garantias individuais (disciplina penal administrativa), fatores de proteção do indivíduo contra aquela genética administrativa da autoridade e da assimetria. Todos esses parâmetros contribuem de forma destacada e indelével para a construção e consolidação desse novo regime jurídico administrativo, fundado no paradigma da Administração Pública democrática.

\section{REFERÊNCIAS}

ALVES, José Ricardo Teixeira. A tutela da boa-fé objetiva no Direito Administrativo. Jus Navigandi, Teresina, ano 13, n. 1917, set. 2008. Disponível em: 〈http://jus.com.br/artigos/11783〉. Acesso em: 03 fev. 2014.

ARISTÓTELES. A Política. Tradução de Nestor Silveira Chaves. 2. ed. São Paulo: EDIPRO, 2009.

ASSEMBLEIA GERAL DAS NAÇÕES UNIDAS. Organização das Nações Unidas (ONU). Declaração Universal dos Direitos Humanos. 10 de dezembro de 1948. Disponivel em: <http://www.humanrights.com/pt/what-arehuman-rights/universal-declaration-of-human-rights/preamble.html>. Acesso em: 27 jan. 2014.

BACELLAR FILHO, Romeu Felipe. Processo administrativo disciplinar. 4. ed. São Paulo: Saraiva, 2013.

BARCELLOS, Ana Paula de. A eficácia jurídica dos princípios constitucionais: o princípio da dignidade da pessoa humana. Rio de Janeiro: Renovar, 2002.

BINENBOJM, Gustavo. Uma teoria do Direito Administrativo: direitos fundamentais, democracia e constitucionalização. 2. ed. São Paulo: Renovar, 2008.

BOBBIO, Norberto; MATTEUCCI, Nicola; PASQUINO, Gianfranco. Dicionário de Política. Tradução de João Ferreira. v. I. 11. ed. Brasília: Editora Universidade de Brasília, 1998.

BONAVIDES, Paulo. Curso de Direito Constitucional. 10. ed. São Paulo: Malheiros, 2003. 
CANOTILHO, José Joaquim Gomes. Direito Constitucional e teoria da Constituição. 7. ed. Coimbra: Almedina, 2003.

CRISTÓVAM, José Sérgio da Silva. O conceito de interesse público no Estado constitucional de direito: o novo regime jurídico administrativo e seus princípios constitucionais estruturantes. 2014. 379 f. Tese (Doutorado em Direito) Programa de Pós-Graduação em Direito da Universidade Federal de Santa Catarina, Florianópolis, 2014.

GÊNESIS. In: A BİBLIA SAGRADA. Tradução ecumênica. São Paulo: Paulinas, 2002.

GIACOMUZZI, José Guilherme. A moralidade administrativa e a boa-fé da Administração Pública: o conteúdo dogmático da moralidade administrativa. São Paulo: Malheiros, 2001.

GONZAGA, João Bernardino. A inquisição em seu mundo. 8. d. São Paulo: Saraiva, 1994.

HABERMAS, Jürgen. Um ensaio sobre a Constituição da Europa. Tradução de Marian Toldy e Teresa Toldy. Coimbra: Almedina, 2012.

JOÃO. In: A BÍBLIA SAGRADA. Tradução ecumênica. São Paulo: Paulinas, 2002.

KANT, Immanuel. Fundamentação da metafísica dos costumes. Coleção "Os Pensadores”. Tradução de Paulo Quintela. São Paulo, Abril Cultural, 1980.

KISTEUMACHER, Daniel Henrique Rennó. A (in) constitucionalidade da Súmula Vinculante no 5. Revista de Direitos Fundamentais e Democracia, Curitiba, v. 9, n. 9, p. 292-311, jan./jun. 2011.

MAURER, Béatrice. Notas sobre o respeito da dignidade da pessoa humana... ou pequena fuga incompleta em torno de um tema central. In: SARLET, Ingo Wolfgang (Org.). Dimensões da dignidade: ensaios de Filosofia do Direito e Direito Constitucional. Porto Alegre: Livraria do Advogado, 2005, p. 61-87.

MIRANDA, Jorge. A dignidade da pessoa humana e a unidade valorativa do sistema de direitos fundamentais. In: MIRANDA, Jorge (Org.). Estudos em homenagem ao Prof. Doutor Martim de Albuquerque. vol. I. Coimbra: Coimbra Editora, 2010, p. 933-949.

. Manual de Direito Constitucional: direitos fundamentais. t. IV. 5. ed. Coimbra: Coimbra Editora, 2012.

MIRANDA, Jorge; SILVA, Marco Antonio Marques da (Coord.). Tratado luso-brasileiro de dignidade humana. São Paulo: Quartier Latin, 2008. 
NOBRE JÚNIOR, Edilson Pereira. O princípio da boa-fé e sua aplicação no Direito Administrativo brasileiro. Porto Alegre: Sergio Antonio Fabris Editor, 2002.

OSÓRIO, Fábio Medina. Direito Administrativo Sancionador. 2. ed. São Paulo: Revista dos Tribunais, 2005.

ROCHA, Cármen Lúcia Antunes. O princípio da dignidade da pessoa humana e a exclusão social. Revista Interesse Público, São Paulo, ano 1, n. 4, p. 23-48, out./dez. 1999.

SARLET, Ingo Wolfgang. As dimensões da dignidade da pessoa humana: construindo uma compreensão jurídico-constitucional necessária e possível. In: . Dimensões da dignidade: ensaios de Filosofia do Direito e Direito Constitucional. Porto Alegre: Livraria do Advogado, 2005, p. 13-43.

. Dignidade da pessoa humana e direitos fundamentais na Constituição Federal de 1988. 4. ed. Porto Alegre: Livraria do Advogado, 2006.

SILVA, Almiro do Couto. O princípio da segurança jurídica (proteção à confiança) no Direito Público brasileiro e o direito da Administração Pública de anular seus próprios atos administrativos: o prazo decadencial do art. 54. da Lei do Processo Administrativo da União (Lei no 9.784/99). Revista da Procuradoria Geral do Estado do Rio Grande do Sul, Porto Alegre, v. 27, n. 57, p. 33-75, 2004.

. Princípio da legalidade da Administração Pública e da segurança jurídica no Estado de direito contemporâneo. Revista da Procuradoria Geral do Estado do Rio Grande do Sul, Porto Alegre, v. 27, n. 57, p. 11-31, 2004.

STAFFEN, Márcio Ricardo; CADEMARTORI, Daniela Mesquita Leutchuk de. A função democrática do princípio do contraditório no âmbito do processo administrativo disciplinar: aproximações entre Elio Fazzalari e Jürgen Habermas. In: SILVA, Maria Teresinha Pereira; ZANOTELLI, Maurício (Coord.). Direito e Administração Pública: por uma hermenêutica compativel com os desafios contemporâneos. Curitiba: Juruá, 2011, p. 23-39.

TAVARES, André Ramos. Princípio da consubstancialidade parcial dos direitos fundamentais na dignidade do Homem. Revista da Faculdade de Direito da Universidade de Lisboa, Lisboa, v. XLVII, n. 1 e 2, p. 313-331, 2006.

Artigo recebido em 29/07/2015

Artigo aprovado em 28/08/2015 